\title{
GANGSTERISMO JOVEM: observação participante e a Escola de Chicago
}

por Breitner Tavares*

WHYTE, William Foote. Sociedade de esquina. Rio de Janeiro: Jorge Zahar, 2005. 390 p.

Sociedade de esquina é um livro pioneiro no que se refere ao estudo da juventude urbana, já que, entre os anos de 1936 a 1940, foi através do convívio com gangues de jovens filhos de imigrantes italianos em uma região segregada de Boston, que o autor pôde desenvolver uma análise distinta das abordagens quantitativas, realizadas até então, sobre os processos de urbanização.

Willian Foote Whyte foi um pesquisador que trouxe uma significativa contribuição à chamada pesquisa qualitativa em ciências sociais, sobretudo no que ficou conhecido no campo dos métodos e técnicas como "observação participante". Sua trajetória de vida pessoal e acadêmica o influenciou significativamente na sua formação enquanto intelectual.

Advindo de um contexto social de classe média, o autor teve um avô médico e foi filho de professor universitário. Seus interesses partiam da economia, passando por ideais de reforma social e apreço pela atividade de escritor.

Após ter concluído seu curso de Economia, obteve uma bolsa de iniciação científica na Universidade de Harvard para uma

\footnotetext{
Doutorando em sociologia pela Universidade de Brasília e bolsista da Fundação Ford. E-mail: breitner@unb.br.
} 
pesquisa que duraria três anos, com a condição de não vincular essa pesquisa à aquisição de créditos em um programa de pósgraduação, no caso um doutorado. Essa liberdade e isenção para a realização da pesquisa influenciaram, sobremaneira, na trajetória e mesmo nos resultados obtidos ao final da experiência.

O ímpeto reformista - desenvolvido ainda no período acadêmico -, leva Whyte a desejar pesquisar, a partir de sua vaga idéia do que seria uma "comunidade pobre e degradada" em Boston, e que ele denominou Cornerville. Esse seria o nome aferido ao lugar onde se materializaria a Sociedade de esquina.

Somente mais tarde, em 1942, sua obra foi submetida a uma banca examinadora de professores da Escola de Chicago, em que seu orientador foi Lloyd Warner e o argüidor foi Louis Wirth, para, posteriormente, adquirir status de tese de doutorado. Para ser qualificada como tese, Whyte teve que incluir, sob exigência de Wirth, em suas análises, referências dos teóricos do campo de pesquisas urbanas da época.

O livro a princípio teve pouca repercussão. Somente anos depois foi reconhecido como um marco, para então se tornar um clássico da literatura sociológica, um livro que superou limites por sua abordagem interdisciplinar, heterodoxa e, ao mesmo tempo, simples, o que torna sua leitura ainda mais agradável.

$\mathrm{O}$ autor, que inicialmente não possuía familiaridade com a literatura sociológica, só a conheceu quando já estava em meio à sua pesquisa. $\mathrm{Na}$ verdade, num período anterior ao início de seu trabalho, em 1937, chegou a freqüentar alguns cursos de metodologia oferecidos em Harvard. Esses cursos foram ministrados por Conrad M. Arensberg e Eliot Chapple, pesquisadores vinculados à abordagem interacionista da Escola de Chicago, com ênfase em estudos sobre organização social, sendo influenciado teoricamente pela perspectiva de pesquisa empírica e de pequenos grupos. Também se relacionou com autores como W. Lloyd Warner, Sólon Kimbal e, finalmente, Elton Mayo, autor que trabalhava o desenvolvimento da teoria da interação. Diante de poucas publicações disponíveis sobre pesquisa 
qualitativa, Whyte leu com muito interesse a hoje a clássica obra dos irmãos Lynd: Middletown (1929). Sua maior preocupação foi a de estabelecer bases mais científicas para a pesquisa social, afastar-se de julgamentos morais que pudessem comprometer a validade de sua abordagem. A exemplo da produção de seu tempo, a idéia era levar a teoria a campo, mas, para Whyte, a questão iria um pouco mais adiante: a teoria adviria da prática de pesquisa empírica.

O livro se desenvolve a partir do material de campo. Os capítulos, distribuídos em três partes principais seguidas de três anexos, se estruturam em função dos grupos dos jovens de Cornerville divididos pelo autor em Rapazes da Esquina e Rapazes Formados. Esses atores sociais revelam, ao longo de seus percursos, aspectos relevantes para a compreensão de sistemas de status e diferenciação sociais no espaço urbano.

Na Parte 1, o autor apresenta seus principais sujeitos sociais pertencentes à geração mais jovem. A esquina enquanto lócus da socialização do espaço urbano é mais importante do que o espaço da casa, já que os jovens só costumam recorrer a ela para se alimentar, para dormir ou quando estão doentes. Nas esquinas da cidade, os nomes de batismo são substituídos por apelidos, e muitos só são reconhecidos dessa forma. Quando alguém é procurado, o primeiro lugar a se buscar é a esquina. Esses grupos, normalmente, são compostos por homens distribuídos nos dois tipos de grupos encontrados na cidade. São eles: os rapazes da esquina e os rapazes formados. Os rapazes da esquina são grupos cujas atividades sociais estão vinculadas à rua, especialmente em algumas esquinas onde se encontram estabelecimentos como: barbearias, lanchonetes, bilhares ou clubes. Essa juventude, no período da Depressão, foi submetida ao desemprego ou a atividades irregulares. Muitos abandonaram a escola antes de completar a oitava série.

Whyte acompanhou os Norton, a gangue de Doc, um rapaz da esquina que foi durante um bom período seu mediador. Doc constituía uma liderança em torno dos outros rapazes. Tinha a fama de "demolir seus rivais", mas admitia isso com certo constrangimento. 
Em seus relatos eventualmente eram narradas as brigas entre as gangues: "Não me lembro de jamais ter perdido uma briga. A gente não teve muitas rixas entre gangues. Havia um bocado de respeito mútuo" (p. 30).

Boa parte da narrativa sobre os rapazes da esquina tem como referencial a biografia de Doc, mas alguns outros membros são considerados, como Danny, Joe e Alex, entre outros. Durante os longos períodos de desemprego, Doc passava quase todo o tempo na esquina e ali se envolvia com atividades relacionadas aos jogos de dados, à venda ilegal de bebidas. O contexto socioeconômico da Depressão foi o referencial que estruturava o tipo específico de alianças resultantes das gangues desses jovens filhos de imigrantes desempregados e segregados espacialmente num bairro pobre (p. 35).

Em suas observações da vida cotidiana de Cornerville, o autor atribui uma especial relevância para a prática dos jogos, que teriam a função de definir posições sociais de prestígio entre os homens. O jogo aumentava o entusiasmo dos Norton - o boliche havia se tornado uma parte regular de sua rotina social. Durante as partidas os jogadores são provocados - "você não vai conseguir!" -, de modo a se intensificar o desafio, desestimulando os desafiantes. Esses jogos ocorriam nas noites de sábado e tornaram-se os principais eventos da semana. O jogo era o principal assunto nos dias úteis, falava-se dos acontecimentos anteriores e sobre o que aconteceria no próximo. Havia, portanto, uma conexão íntima entre o jogo de cada rapaz e sua posição no grupo, observada na maneira de se escolher os parceiros e os ataques verbais que faziam uns aos outros.

Em Cornerville existiam várias associações dirigidas por assistentes sociais da entidade Comunidade Italiana, como foi o caso do Clube Afrodite, uma associação constituída exclusivamente por garotas descritas pelo autor como "atraentes e bem vestidas". O grupo de aproximadamente dez sócias desenvolvia várias atividades comunitárias. Em março de 1938, as garotas passaram a se relacionar com os rapazes da gangue dos Norton. 
$\mathrm{O}$ autor, ao se referir às relações de gênero, expõe vários traços do contexto sexista que regulavam esses encontros entre os jovens. A afetividade típica do amor romântico interage em outros momentos com o tom misógino de alguns garotos.

Alguns rapazes antes de se aproximarem das garotas se referiam de uma maneira hostil a elas. Como observado em alguns comentários de um rapaz da esquina, Joe Dodje, a respeito de Carrie, do Clube Afrodite:

[Joe Dodge] Ela vai com qualquer um por uns trocados. Se você tiver um carro, ela gosta de você. Gosto de passar por ela no meu carro e levantar o nariz... É apenas uma gata vadia (p. 49).

Quando os Norton passaram a sair com as garotas para jogar boliche, isso influenciou sua própria vida social. Alex, um dos rapazes, levava até caixas de doces da loja do tio. Um amigo de Doc, Tony Cardio estava encantado com Helen, a garota mais atraente do grupo. Isso era motivo de furor, pois outros garotos também procuravam disputar as garotas. A associação com as garotas era interpretada pelo autor, como no caso do boliche, um meio de ganhar, manter ou perder prestígio no grupo. Como no caso do boliche. Era essencial para o funcionamento harmônico do grupo que se conservassem e reconhecessem informalmente as graduações de prestígio.

Em relação ao problema da geração e à conseqüente transição para o mundo adulto, o autor considera que esse fator tende a levar à desintegração da gangue. Doc, ao completar 30 anos, é uma liderança em seu bairro, e resolve assumir uma candidatura para um cargo no legislativo; contudo, o fato de não ter dinheiro e emprego intensifica seu estigma da pobreza e de sua pouca instrução escolar. Isso leva Doc, pouco tempo depois, a desistir de concorrer ao pleito. Para tornar-se bem sucedido na política, segundo o autor, o rapaz da esquina deve ser capaz de extrapolar os limites de sua gangue e ampliar continuamente sua esfera de influência social. Tem que conseguir encontrar novos grupos e participar de suas atividades.

Os rapazes formados, por sua vez, constituem uma minoria que superaram o nível de rapaz de esquina por meio de uma educação 
universitária. Esses jovens estão voltados para o imaginário de ascensão e mobilidade social da classe média. $\mathrm{O}$ grupo acompanhado pelo autor foi o de Chic Moreli, um jovem italiano que chegou aos Estados Unidos aos oito anos de idade. Chic era membro do Clube Comunidade Italiana. Clube fundado no interior da escola, no segundo grau, organizado por uma professora de acordo com a avaliação do desempenho acadêmico de cada um. O clube tinha dois objetivos: a ascensão social dos sócios e a melhoria de Cornerville. Promoviam peças teatrais e encontros de literatura italiana, como meio de uma afirmação e luta pelo reconhecimento identitário.

Os membros do Clube eram estimulados a se considerar indivíduos superiores. A afiliação ao grupo dependia não tanto da ação grupal, mas das realizações intelectuais do indivíduo e de sua habilidade em agradar às autoridades externas. Na universidade, a ênfase estava novamente no desempenho intelectual individual.

Em relação à natureza dos grupos, o autor constatou que a natureza e configuração dos rapazes formados e a dos rapazes de esquina são distintas. Enquanto os membros da Comunidade Italiana se estruturavam a partir do desempenho individual de cada um no contexto escolar, a gangue dos Norton surge na esquina e estabelece uma série de atividades diárias como forma de localização e de prestígio social; elas definiam responsabilidades e obrigações dentro do grupo. Os jovens julgavam as capacidades de cada um deles de acordo com a maneira de agir em suas relações pessoais.

Para descrever a diferença entre os grupos, Whyte recorre à cultura do dinheiro com a qual um rapaz de esquina se relaciona pela perspectiva do consumo. Com o objetivo de participar das atividades de grupo, o rapaz da esquina deve partilhar seu dinheiro com os outros. Se ele tem dinheiro, e seu amigo não, espera-se que gaste por ambos. Os rapazes formados encaixam-se distintamente numa economia de poupança e investimento. O rapaz que está na universidade tem que economizar o seu dinheiro, a fim de financiar sua educação e dar início a um negócio ou à sua carreira profissional.

Os Norton e os membros da Comunidade Italiana funcionavam em níveis sociais diferentes, contudo ambos eram representativos de uma grande parte da juventude de Cornerville. 
Outro grupo relevante era o dos assistentes sociais, constituído em sua maioria por ianques de classe média, e, mesmo depois de vinte anos de atividade em Cornerville, nenhum sabia falar italiano. Eles não tinham qualquer conhecimento sistemático dos antecedentes sociais daquelas pessoas em seu país de origem. Agiam no sentido de promover uma adaptação daquela comunidade pobre aos ideais de mobilidade social, mas, na verdade, segundo o autor, poucas conseguiram se adaptar por razões econômicas e de reconhecimento.

Na Parte 2 do livro,o autor se dedica a descrever o gangsterismo presente em Cornerville, bem como o processo eleitoral. Esses fenômenos interferem em várias escalas da vida social de seus habitantes, não se restringindo à juventude.

O contrabando e, mais adiante, a administração do jogo ilegal são as principais formas de enriquecimento de gângsteres. Segundo o autor, a disputa por espaço de comercialização levava, eventualmente, à violência entre gangues rivais envolvidas na prática dos jogos de azar. Contudo, apesar de algumas gangues se envolverem em crimes, como assaltos e roubos, muitas delas conviviam em parcimônia, em função de acordos firmados entre a máfia e a polícia, a qual era muito interessada na "paz", que reduziria conseqüentemente seu trabalho de contenção da violência. A polícia era controlada mediante pagamentos regulares, os "extras", feitos a comandantes e guardas.

O jogo era uma atividade muito popular. Com pequenas quantias qualquer um apostava nos números em função da corrida de cavalo. O jogo era proibido, mas não era imoral. As pessoas, principalmente as mais pobres, sempre apostavam. Nem sempre ganhar o pagamento do prêmio era o mais importante, mas sim pela honra de se vencer.

A administração do jogo era feita por toda uma hierarquia de agentes que iam desde os mais subalternos, aqueles que anotam as apostas, passando por aqueles que arrecadavam quantias importantes (acima de cinqüenta dólares) - chamados "homens cinqüenta por 
cento", os quais tinha maiores comissões e responsabilidades -, e, finalmente, os "cabeças" que controlavam os pagamentos e a mediação com a polícia, políticos e, eventualmente, com juízes responsáveis por processos contra gângsteres.

Pagar e receber "extras" é natural para policiais e para homens que lidam com o jogo. Quando surge algum policial disposto a moralizar o jogo, isso pode causar problema considerável; por outro lado, a imagem dos policiais em Cornerville é negativa; segundo o autor, não é incomum saber de um policial bêbado ou que dorme em serviço.

Em geral, há duas perspectivas dominantes em relação à imagem da sociedade perante as funções da polícia. As pessoas da classe média sentem que ela deve aplicar a lei sem medo ou favorecimentos. As pessoas de Corneville, e muitos dos próprios policiais, acreditam que o agente de polícia deve ter uma relação de confiança e pessoalidade com a população local; dessa forma, será mais viável a resolução de conflitos sem que seja necessário efetuarem-se prisões. Em muitos casos, os policiais são membros da própria comunidade. Alguns deles também gostam de fazer apostas.

Em termos do contexto social, os gângsteres tinham um papel relevante no sentido de propiciarem a empregabilidade. A maior parte dos empregados não tem experiência nem capacitação que os habilite para os empregos no setor privado.

Os clubes sociais de Cornerville também sofriam grande influência política dos gângsteres, como observou o autor no Clube Social e Atlético Corneville. Tony Cataldo, o gângster, e Carlo Tedesco, o rapaz da esquina, disputaram a liderança do Clube Social e Atlético Cornerville. As oposições se tornaram visíveis apenas em duas ocasiões, mas os dois pretendentes tinham consciência do que estava em jogo e, entre crises, manobravam visando sua posição e influência sobre os companheiros do clube.

A carreira política em Cornerville está associada às organizações dos clubes espalhados pela cidade. Eles são organizados 
com a finalidade de seu chefe se preparar para um cargo público e dar a ele o peso eleitoral necessário para conseguir boas conexões políticas. Em troca, espera-se que o chefe promova os interesses dos associados. Família é outra instituição de peso levada em conta no período eleitoral. Em relação ao discurso político, o autor observa nos comícios políticos que os candidatos tentam combinar argumentos associados à questão de classe social e identidade racial. As pessoas de Cornerville dão muito valor a expressões fluentes e enfáticas, mas, ainda assim, não elegem o homem mais eloqüente, pois o mais importante são os vínculos de identificação pessoal com o candidato.

Na Parte 3, o autor expõe suas conclusões acerca da pesquisa em Cornerville. Ele se refere a algumas regularidades encontradas no cotidiano dos jovens. Para ele, as gangues são resultado de relações habituais já presentes na vida de seus integrantes, desde os primeiros contatos sociais na infância, quando viviam próximos uns dos outros. Esses grupos relativamente duradouros surgiram espontaneamente na esquina, e seus integrantes têm entre 20 e 30 anos de idade. A falta de segurança social e a semelhança entre os indivíduos propiciam uma maior interação, já que compartilham dos mesmos problemas e expectativas. Esse é o fator gerador da estrutura grupal.

No contexto do grupo, como considera o autor, é estabelecido um sistema de prestações e contraprestações entre os rapazes da esquina. Há uma distribuição inconsciente de status onde cada um exerce uma função e todos, indistintamente, privilegiam a imagem de liderança. O líder em questão é aquele que deve ser mais solidário, o mais gastador, o "mão aberta". Ele deve convergir o sentido do grupo e representar seus anseios perante os de fora, seja a relação de conflito, competição ou cooperação. O político e o gângster devem tratar com o líder para ganhar apoio de seus seguidores. $\mathrm{Na}$ sua ausência, prevalecem a dispersão e os interesses paralelos. A gangue só existe enquanto unidade na presença do líder. O líder é respeitado por sua isenção. Embora possa haver ressentimentos 
entre alguns dos seguidores, o líder não pode guardar rancor contra nenhum homem do grupo.

Em relação à teoria da interação, o autor procura generalizar alguns aspectos a partir de sua experiência de campo. Para ele, os clubes e as gangues possuem um equilíbrio que se estabelece no momento em que seus membros, a partir da interação, internalizam os padrões costumeiros de organização de suas atividades. Nesse contexto, as características individuais também são resultantes dessa interação, onde se combinam dotes inatos e condições para a experiência coletiva ao longo de uma trajetória de vida.

Um dos objetivos do autor, ao se referir à estrutura social de Cornerville, foi o de demonstrar sua regularidade e organização, que para os seus habitantes faziam sentido. Ali há uma sociedade organizada, que possui suas hierarquias, com partes intimamente entremeadas, e nela são definidas e reconhecidas às posições das pessoas e suas obrigações mútuas. Para o autor, essa perspectiva inclui não apenas o universo de Cornerville, mas também o mundo supranatural.

Mais adiante, Whyte retoma sua perspectiva crítico-reformista ao considerar o problema da mobilidade social em Cornerville. Segundo ele, não é a falta de organização, mas o fracasso de sua própria organização social em se interconectar com a estrutura da sociedade à sua volta que retarda progressões nas escalas sociais ascendentes. Isso explica o desenvolvimento das organizações políticas e mafiosas locais e, também, a lealdade que as pessoas têm à sua raça e à Itália.

A idéia de mobilidade é abordada enquanto um valor construído e apresentado para todas as classes sociais de modo homogêneo. $\mathrm{O}$ autor analisa o quanto esse valor assimilado pela população pobre de Cornerville é difícil de ser efetivado. A imagem de uma sociedade caótica e fora da lei como uma referência para os imigrantes italianos e seus descendentes torna-os indesejáveis diante de outras populações externas ao seu distrito. 
O autor observa que o discurso que qualifica Cornerville como desorganizada é equivocado. Para além dos conflitos presentes no espaço urbano, resultantes da pobreza e da falta de reconhecimento, a sociedade encontra-se em estado de fluxo - mas até esse fluxo é organizado.

Há ainda três anexos. No primeiro, o autor rememora desde o interesse pela pesquisa até a repercussão da obra no meio acadêmico e social. O segundo é escrito por Ângelo Orlandella, um ex-rapaz de esquina que colaborou com a pesquisa de Whyte e que, mais tarde, se tornou um "rapaz formado" em sociologia. O terceiro anexo é constituído por referências bibliográficas selecionadas. 